\title{
As marismas da Baía de Paranaguá: características gerais, modos de apropriação e implicações para a legislação ambiental
}

\section{Salt marshes of Paranaguá Bay (Southern Brazil): ecological characteristics, modes of appropriation and implications to environmental legislation}

\author{
Paulo da Cunha LANA*
}

\begin{abstract}
RESUMO
Este artigo apresenta uma síntese do atual conhecimento das marismas da Baía de Paranaguá, procurando acentuar suas diferenças fisiográficas, florísticas e faunísticas em relação aos manguezais locais. Os usos e formas de apropriação desses sistemas têm sido pouco estudados na região e seus recursos potenciais e suas funções ecológicas têm sido subestimados. Uma análise comparativa dos atributos estruturais e funcionais dos manguezais e marismas regionais acentua a necessidade de revisão da legislação ambiental específica.
\end{abstract}

Palavras-chave: marismas, Baía de Paranaguá, uso e manejo, manguezais, legislação ambiental.

\section{ABSTRACT}

This review presents the current knowledge on salt marshes of Paranaguá Bay (Southern Brazil) and analyses their floristic, faunistic and physiographic differences in relation to local mangroves. Usage and traditional management of local salt marshes have received scant attention in the literature and their potential resources and ecological functions are heavily underestimated. A re-enactment of environmental law is suggested, on the basis of a comparative analysis between structural and functional attributes of local mangroves and salt marshes.

Key-words: salt marshes, Paranaguá Bay (Southem Brazil), use and management, mangroves, environmental law. 


\section{Introdução}

A região entre-marés do complexo estuarino da Baía de Paranaguá é formada por extensas planícies (tidal flats ou mud flats, da literatura inglesa, ou wadden, da literatura alemã,) de baixa declividade, com marés semidiurnas mistas, aporte regular de sedimento e baixos níveis de energia ambiental. Essas planícies podem se apresentar recobertas por formações vegetais muito diversas, dependendo do regime de salinidade e dos níveis de energia ambiental. Angulo e Muller (1990) apresentaram uma primeira tipificação dessas formações nas baías paranaenses, reconhecendo pelo menos seis associações vegetais distintas:

- manguezais com a ocorrência de Rhizophora mangle, Avicennia schaueriana e Laguncularia racemosa;

- manguezais com características transicionais nos setores com salinidade mais reduzida, onde ocorrem a samambaia Acrostichum aureum e a malvácea Hibiscus tilliaceus;

- marismas formadas por bancos monoespecíficos de Spartina alterniflora;

- brejos de maré (tidal marshes), que substituem as marismas e mesmo os manguezais em áreas oligohalinas, colonizados pela taboa Typha domingensis, pela ciperácea Scirpus californicus e pela amarilidácea Crinum salsum;

- pântanos de maré, formações de porte arbóreo não-identificadas, periodicamente inundadas, que se desenvolvem por trás dos brejos de maré (provavelmente caxetais);

- zona de Cladium, formação transicional entre os manguezais e a floresta litorânea caracterizada pelo mangue-de-botão Conocarpus erecta e por elementos da vegetação de dunas.

Devem ser igualmente considerados os baixios arenosos e areno-argilosos não vegetados, que constituem uma das feições mais comuns das regiões estuarinas paranaenses. Apesar do nome que recebem convencionalmente, esses baixios estão frequentemente recobertos por bancos de macroalgas, como Acanthophora spicifera, ou filmes algais de diatomáceas.
As marismas regionais são áreas de deposição marinha recente, com características aluviais, regular ou irregularmente inundadas (COSTA et al., 2003) por águas salinas ou salobras e colonizadas por plantas vasculares herbáceas, tipicamente halófitas. Correspondem aos salt marshes ou saltmarshes da literatura americana e inglesa, ou aos marais salés, da literatura francesa, constituindo, juntamente com os manguezais, os principais sistemas vegetais das zonas úmidas (wetlands) costeiras, em escala global. Na região da Baía de Paranaguá, as marismas, conhecidas tradicionalmente como praturás, ocorrem como associações mono-específicas ou de baixa diversidade, com predomínio da Poaceae (= Graminae) Spartina alterniflora, sob a forma de faixas estreitas e descontínuas, geralmente na margem frontal de manguezais (LANA et al., 1991). Em áreas mais internas do complexo estuarino ou ao longo dos rios de maré, $S$. alterniflora pode ocorrer em associação com $S$. densiflora, espécie com características distintamente xeromórficas, com copas mais altas, densas e persistentes e lâminas foliares estreitas, capazes de se enrolarem para dentro. A penetração de Spartina dentro dos manguezais é excepcional, estando geralmente associada a processos erosivos ou ao desmatamento das árvores.

Os usos e formas de apropriação das marismas regionais têm sido pouco estudados e essas formações têm sido ignoradas ou apenas tangenciadas por diversos estudos que trataram dos manguezais locais (MARTIN, 1992; NAIZOT, 1993; LANA, 2003). Este artigo tem por objetivo apresentar uma síntese do atual conhecimento das marismas do complexo estuarino da Baía de Paranaguá, procurando apontar suas afinidades e diferenças fisiográficas, florísticas e faunísticas com os manguezais locais e fornecer elementos técnicos para uma eventual revisão da legislação ambiental.

\section{Características gerais e processos de formação das marismas regionais}

As marismas se desenvolvem em áreas abrigadas, nas quais o impacto direto de ondas é reduzido. Seu grau de desenvolvimento depende de diversos fatores, entre os quais se destacam a topografia local, a amplitude das marés, os níveis de energia ambiental e o aporte de água doce (ADAM, 1990). São as formações dominan- 
tes nas zonas entre-marés de regiões temperadas, tendendo a ser substituídas por manguezais em áreas tropicais e subtropicais, onde são caracteristicamente menos desenvolvidas (LONG; MASON, 1983). Pelo fato de se distribuírem de forma disjunta e irregular, o que dificulta seu mapeamento pelas técnicas cartográficas convencionais, não há estimativas confiáveis da área total ocupada pelas marismas no mundo.

Com exceção da lista de 80 espécies fornecida por Costa e Davy (1992), não há levantamentos compreensivos ou um tratamento sistemático consistente da flora das marismas da costa atlântica brasileira. Da mesma forma, não foram feitas estimativas a respeito das áreas ocupadas pelas marismas na Baía de Paranaguá, devido à dificuldade de separá-las dos bancos não vegetados imediatamente adjacentes por meio das técnicas convencionais de fotointerpretação.

As marismas da região são formadas basicamente pela gramínea Spartina alterniflora, que pode ocorrer sob a forma de ecofenos distintos, desde formas baixas, com menos de $50 \mathrm{~cm}$ de altura em locais com salinidades superiores a 20 ups, até as formas com mais de $1,50 \mathrm{~m}$, nas gamboas e áreas menos salinas, onde há um maior aporte de nutrientes e uma maior disponibilidade de sedimentos lodosos (LANA et al., 1991).

Uma das características básicas das formações vegetais que se desenvolvem em planícies de marés é a variação na composição específica em função da elevação, mais comum em marismas temperadas, mas também evidentes na costa sul brasileira (COSTA et al., 2003). Padrões de zonação podem ser também evidentes na fauna e na microflora, mas são mais óbvios nas plantas vasculares. Diversos padrões de zonação têm sido descritos para as formações vegetais de latitudes tropicais e subtropicais, particularmente no caso dos manguezais. No entanto, a ausência de um padrão definido de zonação parece ser muito mais comum e isto é particularmente verdadeiro na Baía de Paranaguá (MARTIN, 1992). O único padrão recorrente na região é a distribuição das marismas como faixas estreitas entre os manguezais e o estuário. Nos setores de alta energia, na entrada do complexo estuarino, padrões de zonação vegetal estão obviamente ausentes nas marismas monoespecíficas, restritas a faixas frontais de poucos metros de largura. Já nas áreas oligohalinas ou a montante dos rios de maré, a faixa externa de Spartina alterniflora pode estar acompanhada por uma faixa interna de $S$. densiflora.
Além da vegetação vascular, que constitui seu componente mais óbvio, algas macroscópicas e microscópicas são outro importante componente das marismas locais. Formas aderidas à vegetação vascular enraizada ou flutuando em poças de maré podem crescer rapidamente, permanecendo na marisma ou sendo transportadas pelas correntes de maré. Gêneros de algas comuns nas marismas da Baía de Paranaguá são Ulvaria, Enteromorpha e Cladophora. Da mesma forma, diatomáceas podem estar associadas diretamente às plantas vasculares ou ao seu substrato e mesmo apresentar padrões de zonação ao longo das planícies de maré (obs. pess.)

As marismas locais se formam acompanhando modelos ou sequiências semelhantes àqueles descritos por Long e Mason (1983) e Boorman (1999), no Reino Unido:

- se há deposição de sedimento acima do nível médio das marés de quadratura (MHWN) ou se o tempo contínuo de emersão se aproxima ou ultrapassa seis horas diárias, plantas vasculares podem começar a se estabelecer. Em alguns casos, a colonização vegetal pode ser impedida se os baixios ou esporões recém-formados forem excessivamente móveis ou expostos à ação de ondas. Esses sedimentos podem ser provenientes do mar ou do continente;

- essas plantas aumentam as taxas de sedimentação ao diminuírem a velocidade das correntes junto ao fundo e ao tornarem o substrato mais coeso, devido ao desenvolvimento de seus sistemas radiculares. $O$ processo é ainda intensificado pelo desenvolvimento de películas mucosas, produzidas por diatomáceas e microorganismos e pelas atividades dos próprios invertebrados residentes, com a construção de tubos, apressórios de formas sésseis etc. A fauna bêntica pode ter ainda efeitos contrários, contribuindo para a desestabilização do substrato, pela remoção do filme microbiano ou pelo retrabalhamento do sedimento;

- mais e mais plantas colonizam o baixio recémformado, que se torna completamente vegetado, com exceção de depressões isoladas ou dos canais de drenagem, como as gamboas e os sangradouros temporários;

- a acreção de sedimento pode continuar até atingir níveis apenas alcançados pelas marés mais altas de sizígia; 
- com a contínua acreção de sedimento, passa a ocorrer, em muitos casos, a substituição das marismas por manguezais.

Apesar de pouco estudadas, taxas de acreção devem ser muito variáveis ao longo da Baía de Paranaguá, caracterizada por uma elevada heterogeneidade de ambientes de sedimentação. A única estimativa disponível (SOUZA et al., 2001) é de $1,2 \mathrm{~cm} /$ ano, para a Ilha da Cotinga, no setor euhalino de alta energia, taxa extremamente elevada, quando comparada com outros ambientes costeiros (BOORMAN, 1999). Taxas de acreção tão elevadas podem ser uma das razões dos rápidos processos de recolonização e sucessão dos baixios regionais pela vegetação de marismas e manguezais. Essas seqüências sucessionais não são unidirecionais e reversões podem ocorrer, levando à perda de áreas de marismas já instaladas. Eventos extremamente rápidos de acreção e erosão são evidentes no setor oriental da Baía de Paranaguá, próximo à barra sul de acesso ao complexo estuarino (SOARES et al., 1994).

As marismas são reconhecidas como ecossistemas extremamente produtivos, apesar das dificuldades metodológicas para se estimar suas taxas de produtividade (LANA et al., 1991). Das espécies típicas de marismas, Spartina alterniflora é a que foi mais bem estudada. Estimativas da sua produção primária ao longo da costa atlântica das Américas variam de 101 a $3200 \mathrm{~g}$ de peso seco por $\mathrm{m}^{2}$ por ano (LANA et al., 1991). Em geral, estes valores são subestimativas por se restringirem à produção da fração aérea, ignorando a da fração subterrânea, que é, em geral, muito mais elevada. Por outro lado, tais valores resultam da extrapolação de estimativas obtidas em áreas restritas para áreas mais extensas, procedimento arriscado devido à elevada heterogeneidade das marismas, mesmo em escala local. O mesmo espectro de variação da produtividade encontrado na ampla escala latitudinal pode ocorrer em uma única marisma, dependendo da elevação ou da natureza do substrato. Por fim, estimativas de produtividade das marismas tendem a ignorar o papel das algas do fitoplâncton ou das macrófitas, que podem contribuir com 20 a $50 \%$ da produção total (ROBERTSON; ALONGI, 1992).

A maioria dos estudos sobre a produção primária de Spartina alterniflora foi conduzida na costa leste norte-americana e na Europa. Os poucos estudos a respeito dessa espécie em estuários da costa brasileira tra- taram principalmente da variação sazonal da biomassa, com exceção dos trabalhos de Panitz (1986) e Lana et al. (1991), que procuraram estimar sua produtividade. Este último estudo, desenvolvido no setor euhalino de alta energia da Baía de Paranaguá, descreveu a fenologia da espécie e forneceu algumas estimativas da produção primária das frações aérea e subterrânea. A altura média dos colmos e folhas variou de 43 a $104 \mathrm{~cm}$. A altura média, fora da estação de crescimento, foi inferior a 60 $\mathrm{cm}$. O crescimento ocorreu principalmente de novembro a fevereiro, embora colmos novos brotem durante todo o ano. O florescimento ocorreu de fevereiro a março. A biomassa da fração aérea viva variou de 51 (em maio) a $116 \mathrm{~g}$ de peso seco por $\mathrm{m}^{2}$ (em abril). A biomassa da fração aérea morta foi, em geral, inferior, com pico de $82 \mathrm{~g} / \mathrm{m}^{2}$ no inverno. A biomassa subterrânea viva foi sempre maior do que a das frações aéreas, com um pico em novembro $\left(570 \mathrm{~g} / \mathrm{m}^{2}\right)$ seguido de um decréscimo significativo no final do verão. A proporção biomassa subterrânea/biomassa aérea variou de 1,7 no verão a 8,5 no final da primavera, com uma média de 4,8 . A produção primária líquida da fração aérea foi de 101 a $179 \mathrm{~g} / \mathrm{m}^{2}$ por ano, dependendo do método utilizado. A produção subterrânea foi significativamente maior, atingindo $569 \mathrm{~g} /$ $\mathrm{m}^{2}$ por ano. O turnover foi estimado em 1,01 anos para a biomassa aérea e 1,52 para a subterrânea.

Os baixos valores de produção dessa marisma podem ser atribuídos ao estresse causado pelas elevadas salinidades e pela rápida acreção de sedimento arenoso, que eventualmente levam à substituição da marisma por manguezal. Apesar de ocorrer em área subtropical, o comportamento sazonal da biomassa vegetal foi muito semelhante ao observado em marismas temperadas, com a estocagem de reservas subsuperficiais no final da primavera seguida de alocação para a fração aérea durante o período de verão, antes do florescimento. $\mathrm{O}$ turnover foi mais rápido do que o das populações de Spartina alterniflora da costa leste norte-americana, sugerindo que as temperaturas mais elevadas intensificam os processos de decomposição.

Existe um volume considerável de informações a respeito da fauna bêntica e demersal das marismas subtropicais da costa brasileira, mas permanecem escassos os estudos sobre a fauna das marismas da Baía de Paranaguá (LANA; GUISS, 1991; 1992; NETTO, 1993; GUISS, 1995; NETTO; LANA, 1996; 1997 a 1997b; 1999; PAGLIOSA ALVES, 1997). Mesmo o conhecimento 
taxonômico de algumas das espécies ou grupos numericamente dominantes da macrofauna e da meiofauna permanece insatisfatório ou pouco consistente na Baía de Paranaguá.

Lana e Guiss (1991) registraram 98 espécies macrofaunais em uma marisma do setor euhalino de alta energia da Baía de Paranaguá, com a dominância númerica dos poliquetas Isolda pulchella e Nereis oligohalina, cujas densidades atingiram picos de respectivamente 8000 e $1550 \mathrm{inds} / \mathrm{m}^{2}$. Outras espécies comuns são os gastrópodos Neritina virginea e Littorina flava e o isópodo Sphaeromopsis mourei. Esses animais parecem depender fisicamente da gramínea como habitat, sendo raros em áreas não vegetadas. Apesar de persistentes ao longo do tempo, as populações dessas espécies mostraram marcadas variações temporais, com um forte componente sazonal, muito evidente nas espécies epifaunais, mais comuns nos meses mais frios. Embora menos frequientes no verão, $I$. pulchella e $N$. oligohalina não mostraram variações sazonais tão marcadas. Essas variações não se correlacionaram com mudanças dos parâmetros sedimentológicos e foram provavelmente um reflexo da maior ou menor disponibilidade de alimento, dos ciclos reprodutivos das espécies dominantes e de alterações na intensidade da predação durante o ano. Pagliosa Alves (1997) sugeriu que precipitações intensas podem ser um importante fator regulador de espécies macrobênticas em marismas regionais. Ao contrário do que ocorre em habitats sublitorais na Baía de Paranaguá, a densidade total da macrofauna das marismas foi maior nos meses de inverno, quando há uma maior disponibilidade de detrito, sob a forma de folhas ou colmos mortos. Essa relação se torna ainda mais complexa devido às variações nas taxas de predação, provavelmente mais altas no verão.

Lana e Guiss (1991) evidenciaram ainda que o número total de espécies, as densidades médias e a dominância faunística foram significativamente mais elevados nas marismas do que nos bancos não vegetados imediatamente adjacentes. As populações macrobênticas foram mais estáveis ou persistentes na área vegetada, padrão atribuído à estabilização do substrato proporcionada pela vegetação. A cobertura vegetal atenua perturbações físicas ou biológicas e fornece abrigo, além de reduzir a erosão do sedimento, a imprevisibilidade no aporte de detritos e as taxas de predação. Lana e Guiss (1991) chegaram à conclusão de que a presença de biomassa vegetal, juntamente com variações sazonais na disponibilidade de detritos, seria o principal fator regulador da macrofauna local. Essas conclusões foram contestadas por um estudo posterior de Netto (1993), desenvolvido em marismas de toda a baía, que indicou a importância da textura do sedimento na distribuição das duas espécies dominantes de poliquetas.

Nesse levantamento mais compreensivo da fauna de 20 marismas da Baía de Paranaguá, desde o setor mesohalino até o setor euhalino, Netto (1993) e Netto e Lana (1996) registraram 64 taxa macrofaunais, com dominância numérica (54\% do total) de I. pulchella, $N$. oligohalina e $N$. virginea. Essas espécies ocorreram em 16 dos bancos estudados e apresentaram uma marcada preferência pelas áreas vegetadas. As marismas dos setores internos, com sedimentos muito lodosos e elevados teores de matéria orgânica e umidade, estão praticamente desprovidas de infauna. As formas mais abundantes são as espécies epifaunais $N$. virginea e o isópodo Cassidinidea tuberculata. Já no setor polihalino começa a ocorrer I. pulchella, acompanhada por $N$. oligohalina e pela espécie epifaunal Sphaeromopsis mourei no setor euhalino. A composição e a abundância do macrobentos de áreas vegetadas e não vegetadas são semelhantes em áreas internas da baía, mas muito distintas nas marismas do setor euhalino, com substrato mais arenoso e menores teores de matéria orgânica e umidade. Netto (1993) observou ainda um progressivo aumento do número de espécies desde a porção mais interior do complexo estuarino até as proximidades do canal de acesso.

Com exceção das espécies do gênero Uca, os caranguejos são menos evidentes nas marismas do que nos manguezais regionais. $\mathrm{O}$ caranguejo-do-mangue Ucides cordatus, de valor comercial, não é encontrado nas marismas. Isto provavelmente se deve às maiores taxas de submersão e à maior dificuldade para construção de tocas ou galerias em meio aos densos e intrincados sistemas radiculares de Spartina, principalmente nas formações baixas que se desenvolvem em solos mais arenosos.

O padrão de dominância numérica da fauna por um pequeno número de espécies, caracterizadas por elevadas densidades populacionais, tipicamente observado nas marismas da Baía de Paranaguá, é recorrente nas marismas de áreas temperadas. 


\section{As marismas devem ser consideradas como parte dos manguezais?}

Embora as marismas predominem em latitudes temperadas e os manguezais estejam restritos às costas tropicais e subtropicais, os dois tipos de vegetação podem coexistir quando seus limites de distribuição se superpõem (PATTERSON et al., 1997). Quando isso acontece, como é o caso da Austrália (CLARKE; MYERSCOUGH, 1993), Brasil (LANA et al., 1997), México (LOPEZ-PORTILLO; EZCURRA, 1989) e Estados Unidos (KANGAS; LUGO, 1991), manguezais e marismas tendem a exibir padrões de zonação muito distintos. Em geral, as marismas podem ocorrer tanto como franjas externas (LANA et al., 1991) ou internas (PATTERSON et al., 1997), mas são mais frequientes em zonas menos elevadas do que os manguezais, o que as sujeita a tempos de inundação proporcionalmente maiores.

Há uma série de similaridades estruturais e funcionais entre manguezais e marismas, considerando que ambos se desenvolvem em ambientes semelhantes, sujeitos aos mesmos condicionantes ecológicos, e que se defrontaram e se defrontam com pressões evolutivas similares. Ambos ocorrem na região entre-marés, onde estão submetidos a condições hidrológicas e edáficas muito semelhantes, ou seja, sofrem inundações periódicas, desenvolvendo-se sobre solos salinos e pouco oxigenados. Embora difiram em sua fisionomia, ambos se caracterizam por elevada produtividade primária, pela baixa diversidade florística e por seu papel como refúgios ou locais de alimentação para juvenis de vertebrados e invertebrados marinhos e estuarinos. É por isso que as marismas têm sido tradicionalmente consideradas, por muitos cientistas e pela legislação ambiental, como componentes estruturais e funcionais dos manguezais naquelas áreas em que os dois sistemas coexistem. Este ponto de vista é reforçado pelo fato de Spartina ou outras macrófitas de marismas fazerem parte, geralmente como plantas pioneiras, das séries sucessionais que conduzem à implantação e desenvolvimento dos manguezais.

No entanto, as diferenças estruturais e funcionais entre esses dois ecossistemas são igualmente notáveis. Nas marismas, a biomassa vegetal subterrânea, sob a forma de raízes e rizomas, chega a constituir até $80 \%$ da biomassa total das plantas (ADAM, 1990). Nos manguezais, ao contrário, a maior parte da biomassa está presente sob a forma de troncos e folhas, característica que lhes confere o aspecto de verdadeiras florestas.

A taxa de cobertura do solo por unidade de área é sensivelmente superior nas marismas. As árvores dos manguezais distribuem-se geralmente de forma espaçada e não há cobertura vegetal subarbórea, com exceção das próprias plântulas, das macroalgas que crescem sobre os pneumatóforos e das microalgas que podem formar películas superficiais no sedimento. Com menor freqüência, espécies transicionais marginais, como a pteridófita Acrostichum aureum, podem ocorrer em áreas mais sombreadas, sob a copa das árvores. Essas distintas arquiteturas vegetais criam condições de sombreamento marcadamente distintas nos dois ambientes. Em marismas, principalmente naquelas pouco desenvolvidas e com menor densidade de touceiras, a taxa de insolação sobre o substrato é potencialmente muito maior, devido à ausência de uma copa arbórea (POMEROY e WIEGERT, 1981). Isso pode permitir taxas mais elevadas de produção primária por parte das microalgas que crescem sobre o substrato ou das próprias macroalgas associadas ao sistema. Esses produtores primários são reconhecidamente mais assimiláveis pela fauna associada do que a própria gramínea ou o material vegetal produzido pelas árvores do manguezal, que apresenta elevadas concentrações de material refratário de alto peso molecular (ELLISON; FARNSWORTH, 2001).

As marismas se caracterizam pela ausência de substratos duros, o que exclui toda a epifauna séssil habitualmente encontrada nos troncos de árvores dos manguezais, como as ostras, cracas, tunicados, esponjas, etc. (ROBERTSON; ALONGI, 1992). Em conseqüência, o papel desempenhado por organismos suspensívoros na remoção de material particulado em suspensão pode ser muito mais significativo nos manguezais do que nas marismas.

Ciclos de estocagem de carboidratos, sob a forma de amido nos rizomas subterrâneos, são muito marcados nas marismas, tanto em latitudes temperadas quanto em subtropicais (LONG; MASON, 1983; ADAM, 1990; LANA et al., 1991). Não há evidências de processos semelhantes em manguezais. Por outro lado, há evidências consistentes de que a densidade da infauna, particularmente daquelas espécies que utilizam as raízes de Spartina como substrato ou refúgio, correlaciona-se significativamente com a quantidade de biomassa vegetal subterrânea em 
marismas. Isso foi verificado, na Baía de Paranaguá, para os poliquetas Isolda pulchella e Nereis oligohalina, cujas densidades populacionais são significativamente maiores no final do inverno e início da primavera, quando há um aumento da biomassa de Spartina sob a forma de rizomas (LANA et al., 1991).

Na Baía de Paranaguá, a produção de detritos vegetais (litter ou serrapilheira) nos manguezais se dá principalmente no verão (SESSEGOLO, 1997), com valores de até $18,82 \mathrm{~g} / \mathrm{m}^{2} /$ dia. Valores médios são de $2,89 \mathrm{~g} / \mathrm{m}^{2} / \mathrm{dia}$ no inverno. Este padrão sazonal é claramente invertido nas marismas regionais, nas quais a quantidade de biomassa aérea morta, sob a forma de folhas senescentes ou em decomposição, varia de $31 \mathrm{~g} / \mathrm{m}^{2}$ em dezembro a 82 $\mathrm{g} / \mathrm{m}^{2}$ nos meses mais frios (LANA et al., 1991). Considerando que os detritos vegetais produzidos nos manguezais e marismas podem constituir uma fonte potencial de alimento para espécies detritívoras, é natural esperar profundas diferenças sazonais no comportamento das populações bênticas dos dois sistemas adjacentes. Tal hipótese aguarda testes experimentais, embora Lana e Guiss $(1991$; 1992) tenham demostrado que a densidade de populações bênticas de marismas é significativamente maior nos meses mais frios do ano. Por outro lado, estudos recentes ou em progresso sobre a infauna de manguezais, marismas e bancos adjacentes não vegetados da região (LANA et al., 1997; BROGIM, 2001) têm mostrado de forma consistente que a riqueza específica e a abundância bênticas são significativamente menores nos manguezais do que nas marismas ou bancos não vegetados adjacentes.

Quando associadas aos manguezais, as marismas tendem a constituir formações pioneiras marginais, ou mais raramente ocupam áreas internas desmatadas por fenômenos naturais ou pela ação do homem. Há mesmo sugestões na literatura de que os dois ecossistemas competiriam por recursos limitantes como nutrientes e condições de abrigo, em ambientes costeiros (KANGAS; LUGO, 1991). Os manguezais teriam diversas adaptações que lhes permitiriam dominar ecologicamente as marismas. Sua maior estatura e biomassa seriam responsáveis pelo sombreamento das marismas, de porte subarbustivo. Sua maior complexidade estrutural, com a presença de troncos, ramos e raízes-escora, criaria habitats adicionais para aves, cuja presença maciça pode contribuir para o enriquecimento em nutrientes. As árvores dos manguezais apresentariam ainda vantagens reprodutivas significativas no que se refere à dispersão das sementes. Enquanto as árvores do manguezal são vivíparas e se beneficiam das correntes para dispersão, plantas de marismas em geral se reproduzem de forma vegetativa, através de rizomas, estratégia que reduz sua capacidade de dispersão (LONG; MASON, 1983).

O fato das marismas não se desenvolverem dentro de manguezais tem sido atribuído à atenuação da luz pela copa das árvores. Por outro lado, não deve ser desconsiderada a possibilidade da disputa por espaço pelos sistemas radiculares das duas formações, geralmente concentrados nos $35 \mathrm{~cm}$ subsuperficiais, embora já tenham sido observados até a mais de um metro de profundidade no Paraná.

Uma hipótese alternativa sugere que a distribuição diferencial ou claramente estratificada de manguezais e marismas, quando coexistentes, seria definida não por competição, mas por sua maior ou menor tolerância a condições de emersão e imersão. Processos erosivos recentemente observado no Saco do Limoeiro (Baía de Paranaguá) aparentemente reforçam esta idéia. A erosão de cerca de $50 \mathrm{~cm}$ do estrato superior do substrato expôs as raízes do manguezal local, mas não alterou de maneira significativa as condições de sombreamento. Apesar disso, observou-se um recrutamento rápido de Spartina alterniflora, que formou um banco denso e vigoroso sob a área sombreada de manguezal.

Patterson et al. (1997) atribuíram os padrões de zonação bem marcados de Avicennia germinans e Spartina alterniflora na zona costeira da Louisiana (EUA) a uma série de fatores, que incluem desse o grau de exposição às marés até as taxas de predação dos propágulos. Locais ligeiramente mais elevados forneceriam as condições essenciais para o desenvolvimento dos propágulos de Avicennia, incluindo a menor movimentação horizontal por força das marés, umidade suficiente para evitar a dessecação (mas não excessiva a ponto de causar decomposição) e refúgio contra predadores. Uma vez estabelecidos nesses locais, os manguezais criariam condições de sombreamento, responsáveis pela exclusão da gramínea. Por outro lado, nas marismas internas, o recrutamento de propágulos de Avicennia é inversamente impedido pelas correntes de maré e por uma combinação de atividades de predadores com decomposição mais acelerada pela inundação mais frequiente. No caso, as marismas de Spartina se disper- 
sam primariamente de modo vegetativo, sendo menos afetadas por fatores que controlam a dispersão e germinação de sementes.

Testes críticos para avaliar a existência ou não de competição entre os dois sistemas deveriam incluir experimentos de transplantes cruzados, com a exclusão dos presumíveis competidores. Havendo ou não a competição entre as duas formações, não há dúvidas de que frequentemente as marismas da Baía de Paranaguá tendem a ser substituídas por árvores do manguezal, principalmente por Laguncularia ou Rhizophora, ao longo das séries sucessionais. Esse padrão é mais evidente em baixios com rápidos processos de acreção. A sucessão vegetal pode ser relativamente rápida, como demonstrado por um banco formado na margem esquerda da Gamboa Perequê, no setor euhalino da Baía de Paranaguá. Neste local, uma marisma monoespecífica de Spartina alterniflora formou-se e foi progressivamente invadida e substituída por um bosque de Rhizophora mangle, Laguncularia racemosa e Avicennia schaueriana em um prazo inferior a nove anos.

Em situações excepcionais, marismas podem ser dominantes em áreas tropicais em detrimento dos manguezais. Esse padrão anômalo pode ser atribuído a diversos fatores. A disponibilidade de propágulos pode ser um fator limitante para a fixação e desenvolvimento dos manguezais. Da mesma forma, a dispersão desses propágulos pode ser dificultada em áreas de baixa energia, na ausência de correntes suficientemente competentes para transportar essas estruturas vegetais flutuantes. Além disso, condições locais, como a elevada concentração de sais no solo, resultante de altas taxas de evapotranspiração associadas a inundações escassas, poderiam favorecer o desenvolvimento das marismas.

\section{As marismas como fontes de recursos naturais e como prestadoras de serviços ambientais}

Recursos reais ou potenciais de manguezais ou marismas podem ser classificados em uma série de categorias: a) madeira ou biomassa vegetal para construção ou produção de combustível; b) recursos pesqueiros; c) recursos paisagísticos, como suporte para atividades recreativas e científicas; d) utilização das folhas para sus- tento de herbívoros e pastadores ou complemento alimentar; e) maricultura; f) produção de sal; g) agricultura.

As marismas, tanto em regiões tropicais $\mathrm{e}$ subtropicais quanto nas temperadas, mantêm uma variedade de plantas e animais que podem ser úteis para as populações humanas. Caçadores e pescadores foram os primeiros exploradores desses ambientes e também os primeiros a reconhecerem a sua importância como fonte de recursos alimentares. Da mesma forma, fazendeiros vêm utilizando marismas há centenas de anos, principalmente nas costas temperadas da Europa, como locais de plantio e de criação de gado (LONG; MASON, 1983; ADAM, 1990). Embora essas atividades ainda sejam importantes, mais e mais as marismas se destacam como sítios para atividades recreacionais (turismo, caça e pesca esportiva, observação de aves etc.) e educacionais. Por outro lado, o papel dos manguezais continua excepcionalmente importante para o sustento de populações litorâneas, particularmente nos países em desenvolvimento de regiões tropicais, onde esses sistemas tendem a ser mais desenvolvidos e tradicionalmente mais explorados para fins extrativistas, pesqueiros ou agrícolas. Uma revisão da importância assumida pelos manguezais e do seu potencial de utilização foi fornecida por Hamilton e Snedaker (1984).

A zona costeira, incluindo os estuários e a vegetação marginal, é importante produtora de peixes e crustáceos. Esta é uma atividade econômica importante para as populações ribeirinhas de uma área como a Baía de Paranaguá, ainda que aparentemente secundária para a economia regional. Embora a importância dos fluxos entre marismas e zonas costeiras adjacentes tenha sido estabelecida há muito (NIXON, 1980; BOORMAN, 1999), não se sabe até que ponto a produtividade da vegetação marginal das marismas da Baía de Paranaguá afeta a produção secundária do sistema estuarino adjacente. Há uma marcada distinção entre os recursos pesqueiros disponíveis nas marismas e nos manguezais do complexo estuarino da Baía de Paranaguá. Ao contrário do que ocorre com os manguezais, não existe uma tradição local de exploração de recursos nas marismas. Não há, na região, peixes ou crustáceos que sejam exclusivos das marismas ou explorados apenas nesses ambientes. No entanto, há evidências de que juvenis de muitos peixes e crustáceos utilizam as marismas regionais e as planícies de maré adjacentes como berçário ou criadouro, devido ao refúgio que ali encontram e à maior disponibilidade 
de alimento, seja sob a forma de material vegetal fresco ou de detritos (VENDEL et al., 2003). É o caso, por exemplo, do siri-azul Callinectes sp., cujos juvenis se desenvolvem preferencialmente em áreas rasas vegetadas, com os adultos migrando posteriormente para áreas infralitorais. A ostra-do-mangue Crassostraea rizophorae e o caranguejo-do-mangue Ucides cordatus estão virtualmente ausentes nas marismas, mas o sururu Mytella guyanensis pode ser encontrado aderido às raízes de Spartina alternifora, particularmente em substratos mais lodosos, constituindo recurso alimentar significativo para algumas comunidades locais (MIRANDA, 2004). Juvenis do berbigão Anomalocardia brasiliana são capazes de recrutar em substrato vegetado por Spartina, mas os adultos estão ausentes, provavelmente por causa da dificuldade de se adaptar aos densos sistemas radiculares (GuISS, 1995). O gastrópodo Neritina virginea, utilizado para fins artesanais em diversas regiões do país, é um dos invertebrados mais comuns nas marismas dos setores polihalino e euhalino da baía (LANA; GUISS, 1992), embora não haja qualquer tradição local para sua exploração.

Marismas regionais, em especial na entrada da baía, são ocasionalmente desbastadas para facilitar o trabalho de arrasto na época da tainha. No entanto, a pesca artesanal local tem tradicionalmente dedicado pouca atenção a essas áreas, pela dificuldade de instalar e manipular artefatos de pesca devido à densidade das touceiras. Por outro lado, a pesca esportiva ou recreacional vem aumentando em proporção com a expansão da indústria do lazer nos municípios litorâneos e pode vir a ser, em poucos anos, uma pressão significativa sobre os recursos das marismas e manguezais locais.

Além de sua importância como fontes de recursos naturais, as marismas, manguezais e outras formações vegetais costeiras são considerados feições tamponadoras da erosão marinha. A eficiência dessas formações na redução do impacto dessas marés não depende apenas de sua extensão, mas também da natureza de sua superfície (ADAM, 1990; PETHICK, 1992). Neste sentido, marismas densas podem servir como verdadeiros reservatórios de sedimentos e de várias formas de poluentes e são de fato utilizadas para o tratamento terciário de águas servidas em diversas regiões do mundo (BOORMAN, 1999). Uma crítica que pode ser feita a tais destinações é que a água contaminada pode penetrar no estuário antes que as marés a transportem por sobre as áreas vegetadas costeiras. Apesar da utilização rotineira de marismas para a filtragem de nutrientes (LONG; MASON, 1983; BOORMAN, 1999), não há quaisquer estudos em estuários brasileiros sobre a sua capacidade de suporte como filtros de poluentes. Algumas das marismas mais exuberantes da Baía de Paranaguá são encontradas nos setores meso a oligohalinos, nas proximidades da cidade de Antonina, em locais com despejo pontual de esgoto doméstico. Apesar dessa capacidade de filtragem, evidente para uma série de elementos (NIXON, 1980), a entrada de metais pesados e de outros materiais tóxicos pode eventualmente contaminar a vida silvestre associada às marismas ou manguezais.

Marismas têm sido igualmente utilizadas para fins educativos. Pelo menos em regiões temperadas, são ideais para o estudo de padrões de zonação e para a execução de exercícios descritivos e testes experimentais, devido à sua baixa diversidade específica. Neste contexto, existe um potencial quase ilimitado para o desenvolvimento de projetos de educação científica e educação ambiental nas marismas regionais.

\section{Preservação de marismas e manguezais: pers- pectivas de manejo e o caso específico da legis- lação ambiental}

O manejo de áreas úmidas, que incluem as marismas e os manguezais, tornou-se um tema de preocupação internacional, na medida em que mais e mais áreas deste tipo têm sido drenadas e modificadas. Por muito tempo, wetland foi sinônimo de wasteland (BOORMAN, 1999). A modificação e a conversão das marismas e de manguezais para outras finalidades foram historicamente vistas como empreendimentos de interesse público. Este ponto de vista ainda persiste em muitos países, mas se torna mais e mais questionado, ao ponto de implementar a convenção internacional RAMSAR, de 1971, voltada para a proteção de áreas úmidas.

As características da cobertura vegetal e a qualidade e quantidade da vida silvestre das marismas são, por sua vez, fortemente reguladas pela qualidade e quantidade de habitat disponível. Entretanto, a quantidade de habitat disponível tem diminuído devido à ação do homem. Isto acarretou a redução da diversidade e a de- 
terioração de muitas marismas, tanto em regiões tropicais como temperadas. À medida que as pressões e impactos vão se intensificando, a implementação de práticas de manejo e preservação vai se tornando essencial para a manutenção da biodiversidade e para um rendimento contínuo a longo prazo dos recursos naturais renováveis (LONG; MASON, 1983; ADAM, 1990).

A rápida deterioração de muitas marismas, particularmente evidente nas zonas urbanas, reduziu seu valor para a vida silvestre. Muitas das práticas de manejo atualmente em voga na Europa e nos Estados Unidos e ainda inexistentes na costa brasileira se destinam à melhoria ou restauração dos habitats para espécies de interesse comercial ou recreacional. Práticas de recuperação são necessárias para aumentar a produção de espécies residentes e atender às necessidades de espécies migratórias ou ocasionais. A criação e a reabilitação de marismas têm sido práticas ativas em diversas regiões do mundo, embora não existam registros desses procedimentos na Baía de Paranaguá, nem mesmo nas áreas mais degradadas, junto ao complexo portuário da cidade de Paranaguá.

A importância das marismas tem sido valorada economicamente, particularmente em regiões temperadas, onde são mais bem estudadas e conhecidas. Apesar da existência de estudos de valoração econômica dos manguezais brasileiros (GRASSO, 2000; GLASER, 2003), não há análises equivalentes para as marismas. No entanto, não é difícil perceber, na prática, que muitas das supostas vantagens obtidas com sua conversão para outros fins não se materializaram em termos econômicos ou ambientais.

Não podem ser ignoradas, particularmente nos países em desenvolvimento, as pressões para a conversão de terras de baixo valor comercial de modo a atender as necessidades de populações humanas que crescem rapidamente. Pressões desta natureza sobre manguezais e marismas da Baía de Paranaguá foram descritas por Martin (1992). Não se pode simplesmente afirmar que as marismas e os manguezais locais devem ser preservados sem poder demonstrar os benefícios de tal atitude ou sem propor alternativas razoáveis para atender à demanda da sociedade (MARTIN, 1992; LANA, 2003; MIRANDA, 2004).

Neste sentido, as práticas conservacionistas e preservacionistas do primeiro mundo, consubstanciadas em legislações ambientais mais ou menos restrititivas, podem freqüentemente servir de exemplo, tanto no bom quanto no mau sentido. Historicamente, muitas destas práticas preservacionistas foram voltadas para sítios considerados excepcionais, sob variados pontos de vista, principalmente por suportarem espécies raras ou ameaçadas de extinção. Algumas das primeiras reservas na Inglaterra foram criadas em áreas de marismas, para proteger determinadas espécies, sítios para fins educacionais e pesquisa científica ou paisagens de beleza excepcional (LONG; MASON, 1983).

O manejo de marismas é, em geral, dispendioso e os benefícios dependem dos recursos investidos e da habilidade com que os programas são planejados. Os processos ecológicos prevalecentes nas marismas são complexos e envolvem a interação de muitos fatores físicos e biológicos. O objetivo de qualquer programa de manejo deveria ser a manipulação desses processos de modo a produzir configurações desejadas das associações de plantas e animais.

O interesse pela preservação das marismas é aumentado pela crença de que elas são responsáveis, por meio da exportação de detritos de origem vegetal, pelo enriquecimento das águas estuarinas e costeiras, com consequientes reflexos sobre a economia pesqueira. Uma conclusão óbvia desta premissa, muito questionada desde o influente trabalho de Nixon (1980), é que a capacidade das marismas abrigarem e sustentarem organismos de interesse ecológico e comercial poderia ser afetada ou diminuída por atividades humanas. A expansão portuária, os aterros para urbanização, geralmente por populações de baixa renda, as dragagens, o despejo de resíduos sólidos ou de esgotos domésticos são os impactos mais comuns sobre as marismas e manguezais da Baía de Paranaguá (LANA, 2003).

Para impedir isso, a legislação ambiental vem tentando, há várias décadas, assegurar a proteção destes sistemas com o desenvolvimento de políticas de preservação e conservação, refletidas principalmente na criação de áreas de proteção ambiental. Nos últimos 15 anos, houve um verdadeiro "boom" de legislação ambiental no país, com a criação de um corpo moderno de leis, comparável ao dos países mais adiantados no que se refere à preservação e conservação dos recursos naturais. A rigor, a legislação ambiental brasileira não faz uma distinção explícita entre marismas e manguezais, nem se refere nominalmente às primeiras em qualquer dos seus dispositivos ou resoluções. Da mesma forma, não oferece uma definição legal de "zonas úmidas", embora o endosso brasileiro à convenção Ramsar, pelo Decreto 1.905 
de 16 de maio de 1996, implique a adoção da definição proposta no artigo primeiro da convenção (PATU, 2002). O artigo 2 da Lei n. 4.771, de 15 de setembro de 1965, que instituiu o Código Florestal, considerou como de preservação permanente as florestas e demais formas de vegetação natural situadas "nas restingas, como fixadoras de dunas ou estabilizadoras de mangues". Neste sentido, as marismas poderiam ser legalmente consideradas como áreas de preservação permanente. Por sua vez, os manguezais foram definidos pela Resolução 303 do Conselho Nacional de Meio Ambiente (Conama), de 20 de março de 2002, como "ecossistema litorâneo que ocorre em terrenos baixos, sujeitos à ação das marés, formado por vasas lodosas recentes ou arenosas, às quais se associa, predominantemente, a vegetação natural conhecida como mangue, com influência flúvio-marinha, típica de solos limosos de regiões estuarinas e com dispersão descontínua ao longo da costa brasileira, entre os estados do Amapá e Santa Catarina". Esta definição aparentemente não inclui as marismas, já que estas são mais desenvolvidas justamente ao sul do Estado de Santa Catarina, atingindo sua maior importância nos grandes sistemas lacustres e estuarinos da costa do Rio Grande do Sul.

A inexistência de dispositivos que façam menção nominal e explícita às marismas cria lacunas e ambigüidades legais que certamente trazem e trarão reflexos sobre seu uso e manejo. Por outro lado, a análise comparativa dos atributos estruturais e funcionais de manguezais e marismas aponta para uma urgente necessidade de revisão da legislação ambiental específica, na medida em que os recursos naturais e as funções ecológicas prestadas por estes sistemas podem diferir significativamente.

\section{REFERÊNCIAS}

ANGULO, R. J.; MULLER, A. C. P. Preliminary characterization of some tidal flat ecosystems of the State of Paraná coast. In: SIMPÓSIO BRASILEIRO DE ECOSSISTEMAS DA COSTA SUL E SUDESTE DO BRASIL, 3., 1990. Anais... São Paulo: ACIESP, 1990. p. 158-168 v 2.

ADAM, P. Saltmarsh ecology. Cambridge University Press, 1990. $461 \mathrm{p}$.

BOORMAN, L. A. Salt marshes - present functioning and future change. Mangroves and Salt Marshes, v. 3, p. 227-241, 1999.

BROGIM, R. A. Distribuição espacial e variabilidade temporal da macrofauna bêntica de manguezais da Baía de Paranaguá. Curitiba, 2001. Tese (Doutorado) - Universidade Federal do Paraná. Mimeog.

CLARKE, L. D.; MYERSCOUGH, P. J. The intertidal distribution of the grey mangrove (Avicennia marina) in southeastern Australia: the effects of physical conditions, interspecific competition and predation on propagule establishment and survival. Australian Journal of Ecology, n. 18, p. $307-315,1993$.

COSTA, C. S. B.; MARANGONI, J. C.; AZEVEDO, A. M. G. Plant zonation in irregularly flooded salt marshes: relative importance of stress tolerance and biological interactions. Journal of Ecology, n. 5, p. 91, 2003. No prelo.
COSTA, C.; DAVY, A. J. Coastal Salt Marsh Communities of Latin America. In: SEELIGER, U. (Ed.). Coastal Plant Communities of Latin America. New York: Academic Press, 1992. p. 179-199.

ELLISON, A. M.; FARNSWORTH, E. J. Mangrove community ecology. In: BERTNESS, M. D.; GAINES, S.; HAY, M. E. (Ed.). Marine Community Ecology. Sunderland: Sinauer Press, 2001. p. 423-442.

GLASER, M. Interrelations between mangrove ecosystem, local economy and social sustainability in Caeté estuary, North Brazil. Wetlands Ecology and Management, v. 11, p. 265-272, 2003.

GRASSO, M. Economic valuation of a mangrove ecosystem: Understanding the linkages between local communities and mangroves, Caeté River Bay (PA, Brazil). [S.I.], 2000. Tese (Doutorado) - University of Maryland, College Park. Não publicada.

GUISS, C. Influência da gramínea Spartina alterniflora Loiseleur, 1807 sobre a distribuição e densidade de Anomalocardia brasiliana (Gmelin, 1791). Curitiba, 1995. Dissertação (Mestrado) - Universidade Federal do Paraná. Não publicada.

HAMILTON, L.S.; SNEDAKER, S. C. Handbook for mangrove area management. Unesco, 1984. 123 p. 
KANGAS, P.; LUGO, A. The distribution of mangroves and saltmarshes. Florida. Tropical Ecology, n. 31, p. 32-39, 1990.

LANA, P. C. Manguezais, legislação e gestão de áreas costeiras: o caso da Baía de Paranaguá. Conservação da Diversidade Biológica e Cultural em Zonas Costeiras, APED, Florianópolis, v. 1, p. 313-331, 2003.

LANA, P. C.; GUISS, C. Influence of Spartina alterniflora on structure and temporal variability of macrobenthic associations in a tidal flat of Paranaguá Bay (southeastern Brazil). Mar. Ecol. Prog. Ser., v. 73, p. 231-244, 1991.

LANA, P. C.; GUISS, C. Macrofauna-plant biomass interactions in a euhaline salt marsh of Paranaguá Bay (SE Brazil). Mar. Ecol. Prog. Ser, v. 80, p. 57-64, 1992.

LANA, P. C.; GUISS, C.; DISARÓ, S. T. Seasonal variation of biomass and production dynamics for above- and belowground components of a Spartina alterniflora marsh in a euhaline sector of Paranaguá Bay (SE Brazil). Estuarine Coastal and Shelf Science, n. 32, p. 231-241, 1991.

LANA, P. C., COUTO, E. C. G., AlmeidA, M. V. O. Polychaete distribution and abundance in intertidal flats of Paranaguá Bay (Brazil). Bulletin of Marine Science, v. 60, n. 2, p. 433-442, 1997.

LONG, S. P.; MASON, C. F. Saltmarsh ecology. Glasgow: Blackie \& Son Ltd., 1983. 160 p.

LOPES-PORTILLO, J.; EZCURRA E. Responses of three mangroves to salinity in two geoforms. Functional Ecol., n. 3, p. 355-362, 1989.

MARTIN, F. Étude de l'ecosystème mangrove dans la Baie de Paranaguá, PR, Brésil: Analyse des impacts et propositions de gestion rationnnelle. Paris, 1992. Tese (Doutorado) - Universidade Paris 7.251 p. Não publicada.

MIRANDA, R. B. Modos de apropriação e possibilidades de gestão patrimonial de recursos bênticos da Baía de Paranaguá. Curitiba, 2004. Tese (Doutorado em Meio Ambiente e Desenvolvimento) - Universidade Federal do Paraná. Não publicada.

NAIZOT, T. Géographie de la Baie de Paranaguá (Paraná, Brésil). Apport des données satellitaires à l'étude des marais à mangroves. Paris, 1993. Tese (Doutorado). 426 p. Não publicada.

NETTO, S. A. Composição, distribuição e variabilidade sazonal da macrofauna bêntica de marismas e bancos não-vegetados da Baía de Paranaguá (Paraná, Brasil). Curitiba, 1993. Tese (Doutorado) - Universidade Federal do Paraná. 91 p. Não publicada.
NETTO, S. A.; LANA, P. C. Benthic macrofauna of Spartina alterniflora marshes and nearby unvegetated tidal flats of Paranaguá Bay, Se Brazil. Neritica, n. 10, p. 41-55, 1996.

NETTO, S. A.; LANA, P. C. Influence of Spartina alterniflora on superficial sediment characteristics of tidal flats in Paranaguá Bay (South-Eastern Brazil). Estuarine, Coastal and Shelf Science, n. 44, p. 641-648, 1997a.

NETTO, S. A.; LANA, P. C. Intertidal zonation of benthic macrofauna in a subtropical salt marsh and nearby unvegetated flat (Se Brazil). Hydrobiologia, n. 353, p. 171-180, 1997 b.

NETTO, S. A.; LANA, P. C. The role of above- and belowground components of Spartina alterniflora (Loisel) and detritus biomass in structuring macrobenthic associations of Paranaguá Bay (SE Brazil). Hydrobiologia, n. 400, p. $167-$ $177,1999$.

NIXON, S. W. Between coastal marshes and coastal waters a review of twenty years of speculation and research on the role of salt marshes in estuarine productivity and water chemistry. In: HAMILTON, P.; MAcDONALD, K. B. (Ed.). Estuarine and wetland processes. New York: Plenum Press, 1980. p. 437-525.

PAGLIOSA ALVES, P. R. Efeitos da vegetação e da predação sobre as associações macrobênticas de uma planície de maré da Baía de Paranaguá (Se Brasil). Curitiba, 1997. Tese? Dissertação? Com o autor (Zoologia) - Universidade Federal do Paraná

PANITZ, C. M. N. Produção e decomposição de serapilheira no manguezal do Itacorubi. Ilha de Santa Catarina, Florianópolis, Brasil. São Carlos, 1986. Tese (Doutorado) - Universidade Federal de São Carlos. 601 p.

PATTERSON, S.C.; MENDELSSOHN I. A. A comparison of physicochemical variables across plant zones in a mangal/ salt marsh community in Louisiana. Wetlands. n. 11, vol 1 , 1991. p. 139-161.

PATTERSON, S.; MCKEE, K. L.; MENDELSSOHN, I. Effects of tidal inundation and predation on Avicennia germinans seedling establishment and survival in a sub-tropical mangal/salt marsh community. Mangroves and Salt Marshes, n. 1, p. 103-111, 1997.

PATU, G. N. S. Conservation and wise use of mangrove ecosystems: legislation in Brazil, Colombia, Costa Rica and Nicaragua. Disponível em: <http://www.iucn.org/themes/law/ pdfdocuments/CDGFinalPaperGeorgiaNogueira.pdf $>$ Acesso em :

PETHICK, J. S. Saltmarsh geomorphology. In: ALLEN, J. R. L.; PYE, K. (Ed.) Saltmarshes: Morphodynamics, conservation 
and engineering significance. Cambridge: The University Press, 1992. p. 41-62.

POMEROY, L. R.; WIEGERT, R. G. (Ed.). The ecology of a salt marsh. [S.l.]: Springer-Verlag, 1981.271 p.

ROBERTSON, A. I.; ALONGI, D. M. (Ed.). Tropical mangrove ecosystems. Washington: American Geophysical Union Press, 1992. 329 p.

SESSEGOLO, G. C. Estrutura e produção de serapilheira do manguezal do rio Baguaçu (Baía de Paranaguá, Paraná). Curitiba, 1997. Dissertação (Mestrado) - Universidade Federal do Paraná. Não publicada.
SOARES, C. R. et al. Variações na linha de costa no Balneário Pontal do Sul (PR) no período 1953-1993: um balanço sedimentar. Boletim Paranaense de Geociências, n. 42, p. 161 $171,1994$.

SOUZA, M. C. S. et al. Taxas de sedimentação no complexo estuarino da Baía de Paranaguá, Estado do Paraná, estimadas a partir do método de datação por espectrometria gama $\left({ }^{210} \mathrm{~Pb}\right.$ e ${ }^{137} \mathrm{Cs}$ ): resultados preliminares. In: CONGRESSO DA ASSOCIAÇÃO BRASILEIRA DE ESTUDOS DO QUATERNÁRIO, 8., 2001. v. 1, p. 182-184.

VENDEL, A. L. et al. Fish assemblage in a tidal flat. Archives of Biology and Technology, n. 46, p. 233-242, 2003. 